\title{
A comprehensive review and call for studies on firefly larvae
}

\author{
William Riley ${ }^{\text {Equal first author, 1 }}$, Simone Rosa ${ }^{\text {Equal first author, } 2}$, Luiz Felipe Lima da Silveira ${ }^{\text {Corresp. } 1}$ \\ ${ }^{1}$ Department of Biology, Western Carolina University, Cullowhee, North Carolina, United States \\ 2 \\ 2 Instituto de Recursos Naturais, Universidade Federal de Itajubá, Itajubá, Minas Gerais, Brazil \\ Corresponding Author: Luiz Felipe Lima da Silveira \\ Email address: LIMADASILVEIRAL@WCU.EDU
}

Background. Fireflies (Coleoptera: Lampyridae) are commonly recognized by adult traits, such as a soft exoskeleton, lanterns and associated glow and flash patterns, but their larval stage is far less appreciated. However, fireflies spend most of their lives as larvae, and adults of most species rely solely on resources previously obtained. Therefore, studying the immature stages is imperative towards a comprehensive understanding of fireflies. This paper reviews and indicates key gaps in the biology of firefly larvae based on available literature.

Methodology. We reviewed the literature on firefly larvae to identify key issues and important taxonomic, geographic, and subject biases and gaps.

Results. We found 376 papers that included information on firefly larvae. Only 139 species in 47 genera across eight of eleven lampyrid subfamilies have been studied during larval stages. These numbers reveal a staggering gap, since $94 \%$ of species and over half of the genera of fireflies were never studied in a crucial stage of their life cycle. Most studies on firefly larvae focus on two subfamilies (Luciolinae and Lampyrinae) in four zoogeographic regions (Sino-Japanese, Oriental, Nearctic, and Palearctic), whereas the other subfamilies and regions remain largely unstudied. These studies mainly dealt with morphology and behavior, other subjects remaining greatly understudied by comparison, including habitats, life cycle, physiology and interactions.

Conclusions. Together, these literature biases and gaps highlight how little is known about firefly larvae, and warmly invite basic and applied research, in the field and in the lab, to overcome these limitations and improve our understanding of firefly biology to better preserve them. 
1

2

3

4

5

6 8

9

10

11

12

13

14

15

16

22

23

24

25

26

27

28

29

30

31

\section{A Comprehensive Review and Call for Studies on Firefly Larvae}

\section{William Brent Riley ${ }^{1}$, Simone Policena Rosa ${ }^{2}$ and Luiz Felipe Lima da Silveira ${ }^{1}$}

1 Biology Department, Western Carolina University, 122 Central Dr, Cullowhee, NC 28723, United States of America.

${ }^{2}$ Universidade Federal de Itajubá, Instituto de Recursos Naturais, Av. BPS, 1303, Itajubá - MG, 37500-903, Brazil.

Corresponding Author: Luiz Felipe Lima da Silveira ${ }^{1}$

Biology Department, Western Carolina University, 122 Central Dr, Cullowhee, NC 28723, United States of America.

Email address: limadasilveiral@wcu.edu

\section{Abstract}

Background. Fireflies (Coleoptera: Lampyridae) are commonly recognized by adult traits, such as a soft exoskeleton, lanterns and associated glow and flash patterns, but their larval stage is far less appreciated. However, fireflies spend most of their lives as larvae, and adults of most species rely solely on resources previously obtained. Therefore, studying the immature stages is imperative towards a comprehensive understanding of fireflies. This paper reviews and indicates key gaps in the biology of firefly larvae based on available literature.

Methodology. We reviewed the literature on firefly larvae to identify key issues and important taxonomic, geographic, and subject biases and gaps.

Results. We found 376 papers that included information on firefly larvae. A total of 139 species in 47 genera across eight of eleven lampyrid subfamilies have been studied during larval stages. These numbers reveal a staggering gap, since $94 \%$ of species and over half of the genera of fireflies were never studied in a crucial stage of their life cycle. Most studies on firefly larvae focus on two subfamilies (Luciolinae and Lampyrinae) in four zoogeographic regions (Sino-Japanese, Oriental, Nearctic, and Palearctic), whereas the other subfamilies and regions remain largely unstudied. 
32 These studies mainly dealt with morphology and behavior, other subjects remaining greatly

33 understudied by comparison, including habitats, life cycle, physiology, and interactions.

34

35

36

37

38

39

40

41

42

43

44

45

46

47

48

49

50

51

52

53

54

55

56

57

58

59

60

61

Conclusions. Together, these literature biases and gaps highlight how little is known about firefly larvae, and warmly invite basic and applied research, in the field and in the lab, to overcome these limitations and improve our understanding of firefly biology to better preserve them.

\section{Introduction}

The charismatic fireflies (Coleoptera: Lampyridae) are famous for their flashing adults, but the nearly 2200 described species worldwide show wide-ranging phenotypic and ecological diversity, including the less appreciated diurnal and dark species (Branham, 2010; Martin et al., 2019). For example, adults may use diverse mating signals, including light - as continuous glows or flashes - and pheromones, alone or in combination (De Cock \& Matthysen, 2005, Lewis \& Cratsley, 2008; Stanger-Hall et al., 2018). Because signal diversity is associated with sensor morphology, the use of light and pheromones is accompanied by enlarged eyes and complex antennal morphology, respectively (Stanger-Hall et al., 2018). In addition, most firefly species have been regarded as habitat and/or season specialists as adults (Silveira et al. 2020). Although these data bring about interesting questions, the adult stage is but a flicker in a firefly life cycle, and a staggering lack of information on immature stages significantly obscures our knowledge on the biology of fireflies.

Firefly species are usually semelparous, i.e. they spend most of their lives as larvae. The adult stages only last up to a couple of weeks, in which they reproduce and disperse (Faust, 2017). In fact, adults of most species do not eat, aside from occasional nectaring (e.g. Faust \& Faust, 2014), so they must consume all they need to survive during the larval stage (McLean, Buck \& Hanson, 1972). Except for predatory fireflies (Lampyridae: Photurinae), who lure other fireflies to ambush and prey upon them (De Cock, Faust \& Lewis, 2014), adults of most species live off the energetic supply gathered during their larval stage. Since immature stages bear the bulk of a firefly life cycle, it is crucial to study these semaphoronts to pursue a more comprehensive understanding of firefly biology. However, little to no information can be found in the literature on larval stages of most species as compared to adults. 
Here, we review the literature on firefly larvae, emphasizing the knowns and unknowns in

63

64

65

66

67

68

69

70

71

72

73

74

75

76

77

78

79

80

81

82

83

84

85

86

87

88

89

90

91

available data to provide a starting point for beginners in this field. Specifically, our review provides overall information on crucial biological aspects of firefly larvae, and highlights fundamental open questions.

\section{Survey methodology}

Search criteria and selection of key words

To comprehensively review the literature on firefly larvae, we conducted a systematic survey in the following databases: Zoological Records, Scopus, Biological Abstracts, Biological \& Agricultural Index Plus, Web of Science, Google Scholar, and Biodiversity Heritage Library. We searched for the following combination of terms: Lampyridae + larva, Lampyrid* + larv*, firefl* + larv*, firefl* + gastropod*, lampyrid* + gastropod $^{*}$, and firefl*+snail*. We also used keywords in some languages other than English (Glühwürmchen, Glühwürm, Leuchtkäfer, liciérnag*, pirilamp*, vagalum*, luciol*, lucciol*). As such, our search covered mainly the literature in English, Spanish, Portuguese, Italian, and French. Additionally, we tried to access information in studies in other languages, including Chinese and Japanese, to the best of our knowledge, sometimes not from the original source. We did not set a starting date to include even the oldest works. Finally, we checked the scientific literature list at the Firefly International Network (available at https://fireflyersinternational.net/scientific-literature). Most of the information was obtained directly from the main text, sometimes from abstracts. In some cases, however, where we were unable to access even the abstract, the information was obtained from the sources that cited them (i.e. "apud"; see Supplemental File 2). We disregarded papers that merely mentioned firefly larvae without providing information on this subject, as well as conference presentations, theses and dissertations that were subsequently published, and text books without primary data on larva.

\section{Data analysis}

We addressed the following four questions: (Q1) how many species in each subfamily have at least one study about their larval stages?; (Q2) how often are the subfamilies investigated in the literature (i.e. how many studies deal with each subfamily); (Q3) what is the zoogeographic 
92 distribution of the species surveyed in the studies on larvae?; (Q4) how often are our predefined 93 subjects addressed in the literature?

94 To answer these questions, we scored for each of the 376 papers compiled: the species 95 addressed (Q1), and their respective subfamilies (Q2); the zoogeographic location of the species 96 studied (Q3); and the subjects covered in the study (Q4). A given paper could have multiple tags 97 (e.g. more than one zoogeographic region or subject).

98 We used the most recent valid name for each species. For Q1, only papers with species99 level identification were included, while for Q2 any level of identification beyond the family level 100 was accepted. For the subfamily-level assignment, we followed the classification in Martin et al. 101 (2019), with the addition of Chespiritoinae, recently described by Ferreira, Keller \& Branham 102 (2020) (total: 11). To address the state of knowledge of species per zoogeographic region, we 103 followed the classification of Holt et al. (2013), as follows: Afrotropical, Australian, Madagascan, 104 Nearctic, Neotropical, Oceanian, Oriental, Palearctic, Panamanian, Saharo-Arabian, Sino105 Japanese (total: 11). Upon review, six subjects stood out as being of particular importance to firefly 106 larval biology: morphology - the physical traits of larvae, their function and use in taxonomic and 107 phylogenetic studies; behavior - the general activity of the organisms; habitat - the environments 108 inhabited and what they prefer in terms of factors such as temperature and moisture; life cycle 109 phenology and development of larvae; interactions - the ecological relationships of firefly larvae with predators, prey and parasites; physiology - the functioning of organs, cells, tissues and bioluminescence of firefly larvae, including biochemistry. The results are summarized in 112 Supplemental Files 1 and 2, as well as in barplots (Figs. 1-4) made in R (R Core Team, 2019), 113 using ggplot2 (Wickham, 2009).

114

\section{Results}

We compiled 376 papers that addressed the biology of larval fireflies (Fig. 1). We explored

117 below the knowns and unknowns of larval biology, with special regard to taxonomic, geographic 118 and subject biases in the literature. A full list of literature is provided in Supplemental Files 1 and 1192.

120

Taxonomic bias 
122

123

124

125

126

127

128

129

130

131

132

133

134

135

136

137

138

139

140

141

142

143

144

145

146

147

148

149

150

151

152

Of the $c a .2200$ species of fireflies across 11 subfamilies, 139 species had at least one study with information on larval stages, across 8 of 11 lampyrid subfamilies - roughly $7 \%$ of the total species diversity (Fig. 3). These 139 species span 47 genera, slightly less than half of all lampyrid genera. In three firefly subfamilies, larvae are unknown, revealing a staggering knowledge gap on firefly larval biology. Among these 139 species with known larval stages, 60 are luciolines, 52 are lampyrines, and the remaining 27 species are scattered over six subfamilies: Photurinae (10), Lamprohizinae (6), Ototretinae (3), Cyphonocerinae (1), Psilocladinae (1), Pterotinae (1), in addition to 5 Lampyridae Incertae sedis species (Supplemental Files 1 and 2). When the distribution of studies per subfamily is taken into account, a similar bias can be found (Fig. 4). Nearly $85 \%$ of the studies concentrate in Luciolinae (192) and Lampyrinae (157), followed by Photurinae (50), whereas the other groups have received less attention: Lamprohizinae (12), Ototretinae (7), Psilocladinae (2), Pterotinae (2), Cyphonocerinae (1), and Incertae sedis (17) (Supplemental Files 1 and 2).

\section{Geographic bias}

Most studies on firefly larvae were undertaken in the Sino-Japanese (118), Oriental (88), Nearctic (95), and Palearctic (79) zoogeographic regions (Fig. 4). The other regions - Neotropical (25), Oceanian (12), Australian (11), Panamanian (6), Saharo-Arabian (4), Afrotropical (3), and Madagascan (1) - were far less studied. (Fig. 5; Supplemental File 1). Even though we have not controlled for differences in species richness among regions, regions among the richest in firefly diversity (Neotropical, Panamanian, Afrotropical - cf. McDemortt, 1966) are clearly the ones with fewer studies on larval biology, underlining the geographic bias.

\section{Subject bias}

There was a clear bias towards larval morphology (177), followed by behavior (115), while information on habitat (70), life cycle (81), physiology (68), and interactions (39) were less studied (Fig. 6; Supplemental File 1).

\section{Discussion}

Morphology

Peer) reviewing PDF | (2021:03:59109:2:0:NEW 24 Jul 2021) 
Firefly larvae have a unique combination of characters among beetles (Figs 1-2). These 154 larvae tend to have hardened sclerites - regionalized plates of the exoskeleton - on the dorsum 155 (i.e. terga), venter (i.e. sterna) and sides (i.e. pleurites), which contrast with the more lightly 156 sclerotized body of the adults. However, at least some genera have less sclerotized and/or narrower

157

158

159

160

161

162

163

164

165

166

167

168

169

170

171

172

173

174

175

176

177

178

179

180

181

182

183 sclerites (e.g. Stenocladius Fairmaire; Ohba, Goto \& Kawashima, 1996). Other typical noteworthy traits of firefly larvae include: (i) a retractable head within a prothoracic vault, (ii) sulcated mandibles connected to venom glands, (iii) defensive eversible organs along their sides, (iv) at least a pair of lanterns on their abdomen, and (v) pygopodia - a bundle of membranous tubules outlined by rows of microscopic hooks - on their hindmost segment (Fig. 1A). Nevertheless, not all firefly larvae have all these traits, and some of these can be found in other beetle families as well. For instance, bioluminescence occurs in other beetle families (e.g. Phengodidae, Rhagophthalmidae, some lineages of the Elateridae) (Bocakova et al., 2007; Fallon et al. 2018; Bi et al., 2019). Yet, it is our understanding that the tubular pygopodia with microscopic hooks has only been reported in lampyrid fireflies. Lawrence et al. (2011) coded this trait as "multitubular holdfast organs", and mention that they are known in all lampyrid larvae, but noted that it has evolved independently in a few staphylinid genera.

The head is connected to the prothorax by a membranous neck, an extensible tubular membrane - often bearing elongate sclerites -, which forms a double layered sheath inside the prothorax vault when the head is retracted (Fig. 1A). When the neck is extended it allows the head to be protruded far ahead of the prothorax, a state seen when larvae eat shelled gastropods (Madruga-Rios \& Hernandez-Quinta, 2010; Faust, 2017; Vaz et al., 2021), introducing their heads well within the gastropod shell. Larvae can quickly retract their heads in a defensive response and keep them retracted when resting (Fig 2). The head and its appendages are highly variable across species, particularly the antennae and mouthparts. All known larvae have channeled mandibles connected to venom glands (e.g. Costa, Vanin \& Casari-Chen, 1988; Rosa, 2007; Fu, Ballantyne \& Lambkin, 2012a, 2012b; Vaz, Silveira \& Rosa, 2020). The mandibles might be crossed or largely overlapping in frontal view, and often bear one or two teeth. Nevertheless, the biological meaning of all these mandibular variations in head morphology remains unknown.

Some species (including several Luciolinae and Lampyrinae) have pleural defensive glands along lateral regions of thorax and abdomen, dorsal to tracheal openings, which can be everted as a membranous, single or forked tube that is usually stellate at the tip (Fig. 1A). When disturbed, 
184 those glands are everted and release a strong smell as well as a repellent substance (Fu et al., 2007, 185 Fu et al., 2009), but sometimes only specific threats will trigger the eversion of these glands (e.g. 186 ants - Tyler, 2001a, b; Tyler \& Trice, 2001). Pleural defensive glands have been discovered fairly 187 recently, studied in just a handful of species, and their biological meaning for firefly ecology and 188 evolution is yet to be understood.

189 The pygopodia (Fig. 1A) can be used as hooks to attach to substrates and aid in movement 190 on land and grooming (Archangelsky \& Branham, 1998), as well as to adhere to floating substrates 191 in water (Fu et al., 2005a). Variation in pygopodial morphology has been observed in the number 192 of basal stalks and hook arrangements (e.g. Fu, Ballantyne \& Lambkin, 2012b), but the meaning 193 of such variation still needs to be addressed.

All known firefly larvae are bioluminescent, with the possible exception of an 195 undetermined species - lanternless and allegedly dark - recently reported from the Amazonian 196 tepuis by Kok, van Doorn \& Dezfoulian (2019). Bioluminescence is produced in the paired lanterns (also known as photogenic organs), usually located on the abdomen (Figs 1-2). Most 198 species have only one pair of lanterns as spots on the ventral surface of the abdominal segment 199 VIII (Fig.1A, B), while some others have paired spots on VII and VIII (Fig. 1D, e. g. Pterotus LeConte, 1859; Stenocladius Faimaire 1878), on the pronotum (Nunes et al., 2021), or feature polymorphic patterns of single or paired spots on segments II-VI (Fig. 1E, Lamprohiza Motschulsky 1853; Novak, 2018a). The light becomes more visible when the larva twists or arches their posterior end, but some species have translucent areas in the tergites above the lanterns that make the light visible above the body (Fig. 1C, e.g. Psilocladus Blanchard, 1846 Lamprigera Motschulsky, 1853) (e.g. Costa, Vanin \& Casari-Chen, 1988; Novak, 2018a, b; Vaz, Silveira \& 206 Rosa, 2020).

When comparing the general larval morphology across firefly species, a few patterns arise, 208 which are associated with their habitats and lifestyles. For example, fossorial larvae tend to be 209 rounded, with more extensive membranous areas (Fig. 1A, 2C,D,H, e.g. Photinus Laporte, 1833; 210 Phosphaenus Laporte, 1833), while leaf litter dwellers are flatter, with laterally expanded terga 211 (Fig. 2A, B, E, F; e.g. Photuris LeConte, 1852; Cratomorphus Motschulsky, 1853; Lamprohiza). 212 Some tree-climbing species are very narrow and flat, with elongate legs, reduced pleural regions, 213 and ventral surface well-sclerotized (Fig. 2G; e.g. Pyrocoelia atripennis Lewis, 1896). It is 
214 therefore tempting to think that their overall twig-like morphology is involved in camouflage - a 215 hypothesis yet to be tested.

216 Aquatic species tend to resemble fossorial larvae in outline (i.e. cylindrical, with narrow 217 terga, exposed pleura) (Jeng, Lai \& Yang 2003; Fu, Ballantyne \& Lambkin, 2012b). Most 218 terrestrial (e.g. Photuris spp. - Rosa, 2007) and semiaquatic (Aspisoma fenestrata Blanchard, 219 1839; Archangelsky, 2004) firefly larvae have typical insect spiracles as respiratory openings, but 220 221 aquatic larvae are adapted to exchange gases under water by tracheal gills, apneustic (i.e. without spiracles) or metapneustic (with spiracles on the terminal gill) (Fig. 1A, e.g Aquatica Fu, 222 Ballantyne \& Lambkin, 2010, and some Luciola Laporte, 1833) (e.g. Jeng, Lai \& Yang 2003; Fu, 223 Ballantyne \& Lambkin, 2012b; Ballantyne \& Lambkin, 2013). Aquatic backswimmers (e.g. Sclerotia substriata (Gorham, 1880) and S. aquatilis (Thancharoen et al., 2007) lack gills like the 225 semiaquatic larvae, which have distinctly harder exoskeletons, and use their pygopodia to adhere 226 to floating objects (Fu, Wang \& Lei, 2005; Fu et al., 2005a, 2005b, 2007, 2009; Fu, Ballantyne \& Lambkin, 2012b; Sato, 2019). Interesting ontogenetic shape changes have been reported for the 228 lucioline genus Sclerotia Ballantyne, 2016, where apneustic early larvae become metapneustic in 229 later instars (Fu, Ballantyne \& Lambkin, 2012b). That shape change is followed by a change in mode of life, since benthic apneustic larvae become backswimmers. Some truly aquatic larvae might also feature less sclerotized sclerites, sometimes with terga completely split into two rounded plates (Fig. 2D, e.g Aquatica - cf. Jeng, Lai \& Yang 2003; Fu, Ballantyne \& Lambkin, 2012b; Micronaspis Green, 1948 - Vaz et al., 2021). Highly sclerotizated exoskeletons in arthropods are associated with increased resistance to water loss, but might also hamper cutaneous respiration. Moreover, these are costly to produce, especially where calcium ions are harder to obtain, such as in freshwater environments (Brusca, Moore \& Shuster, 2016). Therefore, at least in aquatic lucioline larvae, a less sclerotized body might be the outcome of adaptation to life in freshwater. Interestingly, a fully aquatic lifestyle evolved multiple times in Ballantyne \& Lambkin, 2012b).

Larvae of some distantly related genera (e.g. the luciolines Abscondita Ballantyne, 242 Lambkin \& Fu, 2013 and Pygoluciola Wittmer 1939, and the lampyrine Micronaspis) bear tergal 243 and pleurite tubercles of unknown function (Fig. 1A, Fig. 2B). It has been proposed that such 
244 tubercles might help Micronaspis attach to the substrate - thus avoid being dragged by sea currents 245 -, fend off predators, or both (Vaz et al., 2021; Nada, Ballantyne \& Jusoh, 2021).

246 Sexual dimorphism in larvae was only reported for a single species, Luciola discicollis 247 Laporte, 1833, from Ghana (Kaufmann, 1965). Interestingly, that species features sexually 248 dimorphic larval lanterns that are larger in males. This trait has been overlooked in other species, 249 since one would need to separately raise and keep exuviae or detailed images to compare after 250 identifying the sex of the emerged adults.

Species in most genera across subfamilies cannot be reliably identified based on larval 252 stages, mostly due to a staggering lack of comparative morphological studies. However, it is 253 noteworthy that larval traits have been successfully used not only to discriminate between species,

254 255

256

257 258

259 260 261 262 263 264 265 266 267 268 269 270 271 272 273 274 but as relevant sources of phylogenetically informative traits (Ballantyne et al., 2019; Vaz et al., 2021).

Understanding the evolution of firefly larval traits has been precluded by two main factors: a lack of descriptive and functional studies, and unsteady phylogenetic frameworks within the Lampyridae, and of the Elateroidea as a whole. The limited breadth of lampyrids ever studied in the larval stage ( $\sim 7 \%$ total species), on top of the staggering taxon-bias (see above), limits any generalisation regarding trait evolution.

Above all, phylogenetic analyses of the Lampyridae have had a relatively limited taxon sampling, not necessarily covering the taxa with known larval stages, and the resulting proposals of classification have been unsteady (Branham \& Wenzel, 2003; Martin et al., 2019). To compound the issue, the relationships within Elateroidea have been ever changing, often in conflict with traditional classification schemes. For example, earlier comprehensive DNA-based phylogenies on Elateroidea found Lampyridae to be sister to either Cantharidae (Bocakova et al. 2007; Kundrata, Bocakova \& Bocak, 2014; Bocak et al. 2018) or to Phengodidae + Rhagophthalmidae (i.e. the "Lampyroidea" hypothesis; McKenna et al., 2015), whilst more recent and advanced approaches have confirmed Lampyridae as sister to the clade Phengodidae + Rhagophthalmidae either sister to or within Elateridae (McKenna et al., 2019; Kusy et al., 2021, Douglas et al., 2021). Together, these limitations hamper any detailed, comprehensive evolutionary analysis of firefly larval traits.

A few interesting patterns emerge when considering "Lampyroidea" within Elateridae, and the Lampyridae as a whole. For instance, the ability to emit light (at least in the larval stages) has 
275 been proposed as a putative synapomorphy for Elateridae including the "Lampyroidea" (cf. 276 Douglas et al., 2021). Furthermore, the channeled larval mandibles are a putative synapomorphy 277 of the "Lampyroidea", even though the condition allegedly evolved independently in 278 Brachypsectridae, Cerophytidae + Jurasaidae, and the elaterid lineage Drilini, as well as and in 279 several adephagan lineages (Beutel, 1995; Costa et al. 2003; Lawrence et al. 2011; Rosa et al. 280 2020).

281

Interestingly, firefly larvae of at least a couple of species (e.g. Lampyris noctiluca 282 (Linnaeus, 1758)) show bioluminescence "leakage" (i.e. invisible to human eyes) through paired 283 lateral spots (over which the exoskeleton is translucent) that match those seen in phengodid larvae 284 (Tisi et al., 2014). These spots have been interpreted as casts of ancestral lanterns, and might be 285 another potential synapomorphy of the "Lampyroidea", although these could also represent an 286 atavic condition. Finally, putative exclusive synapomorphies of Lampyridae include the

287 288 289 290 291 292 293 294 295 296 297 298 299 300 301 302 303 304 305 pygopodia, the pair of lanterns on sternite VIII, and the head fully retractable into the prothorax.

\section{Behavior \& Interactions}

Given the scarcity of studies detailing interactions among firefly larvae and other organisms, behavior and interactions are grouped together.

Larval bioluminescence has been consistently observed as an aposematic warning signal (Underwood, Tallamy \& Pesek, 1997; De Cock \& Matthysen, 1999, 2003), but other functions have been proposed as well (e.g. illumination or intra-specific communication - Sivinski, 1981; Buschman, 1988b). Vertebrate predators learn to avoid firefly larvae by associating their glows to unpalatability (Underwood, Tallamy \& Pesek, 1977; De Cock \& Matthysen, 2003). Many firefly species have a patchy distribution in the larval stage (e.g. Kaufmann, 1965; Kakehashi, Kuranishi \& Kamata, 2013), and seem to agonistically glow in clusters, as if the group was amplifying the visual signal (LS, pers. ob.) - a hypothesis yet to be tested.

Firefly larvae are predators with extra-oral digestion, and a notorious preference for soft bodied invertebrates, notably gastropods. In fact, specialization in gastropods is so extreme that firefly larvae can recognize the chemical signature of snail and slug slime to decipher their direction (Fu \& Meyer-Rochow, 2013; Sato, 2019). Even marine fireflies prey on gastropods (e.g. Micronaspis gabrielae Vaz, Rocha \& Silveira, 2021 - Vaz et al., 2021). Firefly larvae mastered gastropod-eating through a menagérie of complex behaviors, including snail-riding (climbing the 
306 shell and biting from above, e.g. Lampyris noctiluca - Tyler, 2002), snail-lifting (lifting the snail 307 and holding it in the air before biting, e.g. Micronaspis gabrielae - Vaz et al., 2021), and tracking 308 of mucus trail (Pyrocoelia atripennis - Sato, 2019). At least under lab conditions, firefly larvae of 309 many species would feature "congregating feeding behavior", upon which several larvae will eat

310 311 312

313 314 315 the same prey (e.g. Fu \& Meyer-Rochow, 2012, Nunes et al., 2021). This phenomenon was never documented in the field, and is still largely unstudied.

Alternatively, the fossorial larvae of several Photinini LeConte, 1881 species are known to eat (e.g. Hess, 1920; Archangelski and Branham, 2001) or even specialize in earthworms (e.g. De Cock 2000), while at least some Photuris species are more generalist, eating gastropods, earthworms, termites and even decaying matter (Buschman, 1984; Rosa, 2007).

Larvae will use the sulcate, distally opened mandibles to pierce and inject a supposedly neurotoxic venom to paralyze their prey (Fig. 1A) (Williams, 1917a; Hess, 1920; Fabre, 1924; Tyler, 2002; Walker et al., 2018). Once the prey is paralyzed, the prey's flesh will be cut by the larva's mandibles into smaller pieces, dissolved with digestive enzymes that are regurgitated from the midgut, then sucked into the oral cavity (e.g. Sato 2019). Since firefly larvae are very effective at eating gastropods, the former have been proposed as biological controllers of the latter (e.g. Fu et al., 2005; Fu and Meyer-Rochow, 2012, 2013; Sato, 2019). Despite the overall enthusiasm with that possibility, studies measuring the success of firefly larvae as biological controllers at agricultural scales are lacking.

The range of activity of adult fireflies is very broad, with some being active only at the dusk or late night, some only for short spans, while others are active for hours on end (MadrugaRios \& Hernández-Quinta, 2010; McLean, Buck \& Hanson, 1972). However, larval behavior is far less researched than that of the adults; larvae are assumed to be almost strictly nocturnal but might have been overlooked during the day. In fact, Lampyris larvae have been spotted crawling in daytime, searching for pupation sites (Tyler, 2002). During the day, terrestrial larvae are presumed to rest in soil, leaf litter, and under stones (McLean, Buck \& Hanson, 1972; Faust, 2017), rock crevices (Vaz et al., 2020), or inside bromeliads (Vaz, Silveira \& Rosa, 2020). At night they appear on the surface, crawling among grass, weeds, and sometimes climbing up a few inches on stems, particularly if the weather is damp (Faust, 2017).

Aquatic firefly larvae dwell in slow-moving rivers and ponds. They either anchor themselves with their pygopodia or swim near the surface in a squirming back swimming motion 
337 to search for prey (Jeng, Lai \& Yang 2003; Fu, Ballantyne \& Lambkin, 2012b). Larvae of at least 338 some aquatic species (e.g. Aquatica ficta - Ho et al., 2010) float on water and take on currents, 339 which helps larvae disperse within the same habitat. Moreover, the salt-water adapted Micronaspis 340 floridana Green, 1948 larvae were observed taking on a "canoeing” behavior, upon which the larva 341 would better float (Vaz et al., 2021), and possibly disperse on sea currents. Interestingly, aquatic 342 larvae will climb to land and search for pupation sites off water (Ho et al., 2010).

Semi-aquatic larvae dwell in the soil and leaf litter on river banks and pond margins, but

344 345 346

347 348 349

350 351

352

353 354 355 356 357 358 359 360 361 362 363 364 365 move to the water for short periods when foraging (e.g. Fu et al., 2005a, 2006a). Tree-climbing larvae will often dwell on the ground but will climb trees when tracking prey, by following gastropod mucus trails (e.g. Madruga-Rios \& Hernández-Quintas, 2010; Sato, 2019). SR and LS have oftentimes found fossorial and tree-climbing firefly larvae in the Atlantic Rainforest (Brazil), but never managed to raise these to the adult stage.

Firefly larvae are chemically defended and aposematic, which usually protects them from generalist predators (DeCock \& Matthysen, 2001). In fact, only a few predators of terrestrial firefly larvae have been reported - mostly birds (Lloyd, 1973a). In freshwater, scyllarid lobsters, stream crabs, dragonfly larvae, and Taiwanese tilapia are known predators of aquatic firefly larvae (Ho \& Chiang, 2002 apud Ho et al., 2010). Predators that specialize in firefly larvae were never reported. However, a wide array of parasites of firefly larvae has been reported (Lloyd, 1973a; Day, 2011; Faust, 2017). These include entomopathogenic fungi (cf. Day, 2011; Foo, Seelan \& Dawood, 2017), nematodes, and parasitoid tachinid and phorid flies (Lloyd, 1973a; Faust, 2017). Interestingly, but consistent with their mostly diurnal behavior, parasitic wasps were never reported to parasitize firefly larvae.

To avoid enemies, firefly larvae often have color patterns that match their backgrounds (cf. Faust, 2017). Some species will go dark and feign death if discovered by a potential predator (e.g. Darwin, 1839; Fu et al., 2007). Otherwise, larvae typically glow when disturbed, as a warning to potential predators, or evert repugnatorial glands if they can (Fu et al., 2009).

Firefly larvae often carry many mites, especially in the prothorax vault (Faust, 2017; LS pers. ob.). These mites are likely commensals, living on the leftovers of firefly larvae. Likewise, fireflies can be commensals on nests of termites or ants. Larvae of some North American Pleotomodes species and the North African Pelania mauritanica have been found at the entrance or in chambers within ant nests, but no obvious positive interactions between lampyrids and ants 
368 are known (Cros, 1924; Sivinski et al., 1998). These lampyrid larvae do not feed on ants, and the 369 ants do not seem to notice the presence of the larvae or adult fireflies that live in their nests (Cros, 370 1924; Sivinski et al., 1998). These ant nests might offer damper conditions than those found 371 outside, given that these firefly species occur in arid environments. Undescribed larvae of a 372 Psilocladus sp. (Psilocladinae) and another unidentified species (possibly a Lampyrinae: 373 Cratomorphini), have been found inside termite nests in Brazil (SR, pers. ob.). These larvae are 374 entirely unpigmented, a common feature in fossorial beetle larvae (e.g. cantharid Macromalthinus 375 Pic, 1919 (Biffi \& Casari, 2017) and Jurasaidae species (Rosa et al. 2020)). Under laboratory 376 conditions, Psilocladus larvae of two species studied by our group readily ate termite workers, 377 consistent with the possibility that they live on termites in the field (Vaz et al. 2020; SR, pers. ob.). 378 Matriphagy has been hypothesized in at least one species, Phausis inaccensa LeConte, 379 1878, where larviform females partake in egg guarding behavior (Faust \& Forrest, 2017). In that 380 species, larvae refused to eat food items readily eaten by firefly larvae under lab conditions. Given 381 that the dead body of the mother was separated from the offspring, the authors proposed that 382 matriphagy might be important in normal development of $P$. inaccensa larvae- a hypothesis yet 383 untested.

384

385

386

387 388 389

390

391

392

393

394

395

396

397 398

\section{Habitat}

Firefly larvae are adapted to a diverse array of microhabitats. Terrestrial larvae might be tree-climbers, crawl over or under the leaf litter, or even be fully fossorial - for each microhabitat typical morphological traits can be associated (see above). Terrestrial and semi-aquatic larvae will often be found under rotten logs or rocks, but one species - the only known psilocladine larvae is associated with bromeliads (Vaz, Rosa and Silveira, 2020). Aquatic larvae live in streams, ponds, mangroves, rocky outcrops, and aquatic crop fields; dwell on the bottom, or are backswimmers (e.g. Ho et al., 2010; Vaz et al., 2021). Both terrestrial and aquatic species are known to build hypogeous, mud pupal chambers (e.g. Bicellonycha Motschulsky, 1853 - Cicero, 1982; Aquatica - Ho et al., 2010). Many others pupate on leaflitter (e.g. Cratomorphus - Campos, Silveira \& Mermudes, 2018), or hang off the ground by the pygopodia on vegetation (e.g. Pyractomena - Alchangelsky \& Branham, 1998). Interestingly, because most firefly larvae specialize in gastropods, habitat displacement could have contributed to lampyrid radiation, a hypothesis never formally addressed. 
The habitat requirements for larval survival are often different from those of adults, which

400

401

402

403

404

405

406

407

408

409

410

411

412

413

414

415

416

417

418

419

420

421

422

423

424

425

426

427

428

429

must be taken into account in conservation policies. In other words, the lack of knowledge about larval needs might undermine the success of the conservation firefly species.

Life cycle

Fireflies live for approximately one or two years, depending on the species, usually spending most of that time as larvae. Under laboratory conditions, larvae raised from eggs usually took 2-11 months to reach pupal stage, through 4-7 instars (Bess, 1956; Rosa, 2007; Ho et al., 2010; Viviani, Rosa \& Martins, 2012). However they may take even longer to pupate. For example, larvae of the firefly Pyrocoelia pectoralis have rather plastic life cycles that alternate between 12 years (Fu \& Meyer-Rochow, 2013).

Most species living in temperate climates hatch in the summer, and live as larvae until spring before pupating. Known exceptions are Ellychnia corrusca, which pupate in the fall, as well as Pyractomena borealis and some European Lampyrini, which pupate during spring (Álvarez \& De Cock, 2011; Faust, 2012). Seasonality of tropical species is far less understood. A few tropical multivoltine species have been reported, which are known to pupate in the rainy season (Vaz et al., 2020; Vaz et al., 2021).

\section{Physiology}

Few studies have addressed the physiology of firefly larvae to various degrees. However, these span a wide range of topics, including larval respiration (e.g. Buschmann, 1984a), molecular properties of bioluminescence (e.g. Viviani at al. 2004; Tisi et al., 2014), neurophysiology (e.g. Vencl et al., 2012), genome-wide adaptations to aquatic lifestyles (Zhang et al., 2019), and the developmental origin of larval lanterns (Hess, 1922; Tonolli et al., 2011; Stansbury \& Moczek, 2014). Otherwise, all basic aspects of larval firefly physiology remain unknown (e.g. venom synthesis and metabolism, digestion, hormone signaling and molting, osmoregulation and metabolic waste management, etc.). Only a few species were investigated in studies of firefly larval physiology. Thus, a broader taxonomic sampling is sorely needed to assess the level of generalization of these findings.

Fireflies are known to inject venom and to extra-orally digest prey with saliva, but the exact composition, synthesis, and variations in these fluids remain unknown. Furthermore, freshwater, 
430 estuarine and even marine species of fireflies exist, but how they cope with ion regulation is yet to 431 be discovered. Importantly, the physiology of molting in firefly larvae - which would provide 432 insight into the widespread paedomorphosis in fireflies - remains unexplored (but see Chanchay 433 et al., 2019).

Buck (1948) addressed the physiology of firefly bioluminescence and summarized early scientists' contributions on this topic. Early works on the source of firefly light contrasted two hypotheses: endogenous versus bacterial (Williams 1917b, Harvey \& Hall, 1929; Hasama, 1942). The endogenous hypothesis has gained consensus after the discovery of luciferin, luciferase and their chemical reaction. Tisi et al. (2014) demonstrated the presence of low-level bioluminescence throughout the body in all life stages of L. noctiluca suggesting a secondary role of luciferase.

Carlson $(1965,1968 \mathrm{a}, \mathrm{b})$ investigated the bioluminescence of Photuris larvae under effects 441 of drugs, electrical stimulation and oxygen concentration to compare larval and adult 442 pseudoflashes (i.e. artificially simulated). His results were seminal to later research on the 443 neurophysiological control of Photuris lanterns (e.g. Oertel \& Case, 1976; Christensen \& Carlson, 444 1981, 1982; Vencl et al., 2012). Of particular interest was the finding that larval glows were 445 induced by irritation of lateral abdominal setae, and mediated by octopamine, which is supposed 446 to be homologous to vertebrate noradrenaline (Vencl et al., 2012).

Harvey \& Hall (1929) have ablated the larval lanterns of an unnamed species, in an 448 experiment suited to test whether the larval light was endogenous or bacterial. The few individuals that survived to the adult stage had wild type lanterns. Assuming that these researchers successfully ablated the larval lanterns, their results suggest that the adult lantern tissues are not developed from larval ones. Thus, adult lanterns might not be homologous from the developmental perspective. Future studies addressing the evolutionary and developmental origin of larval and adult lanterns are of utmost importance to understand the evolution of fireflies. For example, whether the larval lantern tissues of the "lampyroid" families Phengodidae and lampyridae are homologues, to our knowledge, is an open question.

\section{Conclusions}

The information available on firefly larvae is rich and valuable, although heavily concentrated on a few taxa, regions, and subjects. Luciolinae is by far the best known subfamily 
461 larvae deal with morphology, followed by behavior. Other subjects remain greatly understudied 462 by comparison, including habitat, life cycle and interactions. Together, these literature biases and 463 gaps highlight how little is known about firefly larvae.

464 The huge overarching gaps in firefly biology have many problematic implications. For 465 example, identification of firefly larvae is currently impossible without raising them to adult stage. 466 On one hand, species discrimination among firefly species is mostly dependent upon adult male 467 traits (e.g. McDermott, 1964). On the other hand, identification methods based on DNA (e.g. DNA 468 barcoding) depend on comprehensive taxon and geographic sampling (e.g. Joly et al., 2014), both 469 currently lacking in available databases and literature on fireflies. Therefore, the lack of 470 information on larval morphology and general biology renders species identification of immature 471 stages virtually impossible.

472 Ultimately, we need more information on firefly larvae to more deeply understand the 473 evolution of the Lampyridae. How do we identify larval fireflies? Where and for how long do they 474 live? When are they active and not? What do they eat? What's in their venom? How do ontogenetic 475 shape changes correlate with larval ecology? How do all these traits evolve within and across 476 firefly lineages? Moreover, how much of firefly diversity was driven by adaptive processes 477 associated with larval biology? Do larval and adult lanterns have the same developmental origin? 478 Future studies targeting these issues are sorely needed to overcome knowledge shortfalls and pave 479 the way towards a more comprehensive understanding of fireflies.

480

481 Acknowledgements

482 We thank Bruna P. Oliveira for drawing Fig. 1B, J. Brawley and S. Hoskins 483 for critically reviewing the manuscript. LS was funded by the Western 484 Carolina University Biology Department. 485

References

Álvarez JG, De Cock, R. 2011. The biology and distribution of glow-worms (Coleoptera: 488 489 Lampyridae) in Spain. In Day JC, ed. Lampyrid: The Journal of Bioluminescent Beetle Research Volume 1. Oxfordshire: Brazen Head Publishing, 22-31. 
490

491

492

493

494

495

496

497

498

499

500

501

502

503

504

505

506

507

508

509

510

511

512

513

514

515

516

517

Archangelsky M, Branham MA. 1998. Description of the preimaginal stages of Pyractomena borealis (Randall, 1838) (Coleoptera: Lampyridae), and notes on its biology. Proceedings of the Entomological Society of Washington 100:421-430.

Archangelsky M, Branham M. 2001. Description of last instar and pupa of Pyropyg nigricans (Coleoptera: Lampyridae, Photinini) and comparison with larvae of other Photinini genera. The Canadian Entomologist 33(2): 155-164 DOI: 10.4039/Ent133155$\underline{2}$.

Archangelsky M. 2004. Description of the last larval instar and pupa of Aspisoma fenestrata Blanchard, 1837 (Coleoptera: Lampyridae) with brief notes on its biology. Tijdschrift voor Entomologie 147:49-55.

Ballantyne LA, Lambkin CL. 2013. Systematics and phylogenetics of Indo-Pacific Luciolinae fireflies (Coleoptera: Lampyridae) and the description of new genera. Zootaxa 3653:1-162 DOI: 10.11646/zootaxa.3653.1.1

Ballantyne LA, Lambkin CL, Ho J-Z, Jusoh WFA, Nada B, Nak-Eiam S, Thancharoen A, Wattanachaiyingcharoen W, Yiu V. 2019. The Luciolinae of S. E. Asia and the Australopacific region: a revisionary checklist (Coleoptera: Lampyridae) including description of three new genera and 13 new species. Zootaxa: 4687(1): 1-174. DOI: 10.11646/zootaxa.4687.1.1

Bess HA. 1956. Ecological notes on Lamprophorus tenebrosus (Walker)(Coleoptera: Lampyridae), an enemy of the giant African snail. Proceedings, Hawaiian Entomological Society 16(1):24-29.

Beutel RG. 1995. Phylogenetic analysis of Elateriformia (Coleoptera: Polyphaga) based on larval characters. Journal of Zoological Systematics and Evolutionary Research 33(2):145-171 DOI: 10.1111/j.1439-0469.1995.tb00222.x

Bi W-X, He J-W, Chen C-C, Kundrata R, Li X-Y. 2019. Sinopyrophorinae, a new subfamily of Elateridae (Coleoptera, Elateroidea) with the first record of a luminous click beetle in Asia and evidence for multiple origins of bioluminescence in Elateridae. ZooKeys 864:79-97 DOI: 10.3897/zookeys.864.26689 
518

519

520

521

522

523

524

525

526

527

528

529

530

531

532

533

534

535

536

537

538

539

540

541

542

543

544

Biffi G, Casari SA. 2017. Comparative morphology of immatures of neotropical Chauliognathinae (Coleoptera, Cantharidae). Zoologischer Anzeiger 267:111-138. DOI: 10.1016/j.jcz.2017.02.003.

Bocak L, Motyka M, Bocek M, Bocakova M. 2018. Incomplete sclerotization and phylogeny: the phylogenetic classification of Plastocerus (Coleoptera: Elateroidea). PLoS One 13, e0194026 DOI:10.1371/journal.pone.0194026

Bocakova M, Bocak L, Hunt T, Teraväinen M, Vogler AP. 2007. Molecular phylogenetics of Elateriformia (Coleoptera): evolution of bioluminescence and neoteny. Cladistics, 23(5), 477-496.

Branham MA. 2010. Lampyridae. In: Leschen RAB, Beutel RG, Lawrence JF, ed. Handbook of Zoology. Coleoptera, Beetles. Vol. 2: Morphology and systematics (Elateroidea, Bostrichiformia, Cucujiformia partim). Berlin: Walter de Gruyter, 141-147 DOI: $10.1515 / 9783110911213.141$

Branham MA, Wenzel JW. 2003. The origin of photic behavior and the evolution of sexual communication in fireflies (Coleoptera: Lampyridae). Cladistics 19(1):1-22 DOI: 10.1111/j.1096-0031.2003.tb00404.x

Brusca RC, Moore W, Shuster SM. 2016. Invertebrates. 3rd ed. Suderlan: Sinauer Associates, Inc.

Buck JB. 1948. The anatomy and physiology of the light organ in fireflies. Annals of the New York Academy of Sciences 49:397-482 DOI: 10.1111/j.1749-6632.1948.tb30944.x

Buschman LL. 1984. Biology of the firefly Pyractomena lucifera (Coleoptera: Lampyridae). Florida Entomologist 67:529-542.

Buschman LL. 1988. Light organs of immature fireflies (Coleoptera: Lampyridae) as eyespot/false-head displays. The Coleopterists Bulletin 42(1):94-97.

Campos SVN, Silveira LFL, Mermudes JRM. 2018. Systematic Review of the Giant Firefly Cratomorphus cossyphinus: Sexual Dimorphism, Immature Stages and Geographic Range (Coleoptera: Lampyridae). Annales Zoologici 68(1):57-84. DOI: $\underline{10.3161 / 00034541 \text { ANZ2018.68.1.003 }}$ 
Carlson AD. 1965. Factors affecting firefly larval luminescence. The Biological Bulletin 129(2):234-243.

Carlson AD. 1968a. Effect of drugs on luminescence in larval fireflies. Journal of Experimental Biology 49:195-199.

550

Carlson AD. 1968b. Effect of adrenergic drugs on the lantern of the larval Photuris firefly.

551 Journal of Experimental Biology 48:381-387.

552

Chanchay P, Vongsangnak W, Thancharoen A, Sriboonlert A. 2019. Reconstruction

553

554 of insect hormone pathways in an aquatic firefly, Sclerotia aquatilis (Coleoptera: Lampyridae), using RNA-seq. PeerJ 7:e7428 DOI: 10.7717/peerj.7428

555

Christensen TA, Carlson AD. 1981. Evidence for non-modulatory octopaminergic transmission mediating luminescence in larval fireflies. Society for Neuroscience Abstracts 7:413.

558

Christensen TA, Carlson AD. 1982. The neurophysiology of larval firefly luminescence:

559

560 direct activation through four bifurcating (DUM) neurons. Journal of comparative physiology 148:503-514 DOI: 10.1007/BF00619788

561

Cicero JM. 1982. The genus Bicellonycha in the United States with descriptions of a new

562

563 species and subspecies (Coleoptera: Lampyridae, Photurinae). The Coleopterists Bulletin

564 36(2): 270-278.

565

Costa C, Vanin SA, Casari-Chen AS. 1988. Larvas de Coleoptera do Brasil. São Paulo: Museu de Zoologia da Universidade de São Paulo. Cerophytidae (Elateroidea: Coleoptera). Systematic Entomology 28:375-407. DOI: 10.1046/j.1365-3113.2003.00219.x

572 Cros A. 1924. Pelania mauritanica L. variations - moeurs - evolution. Bulletin de la 573 Société d'histoire naturelle de l'Afrique du Nord 15:10-52.

Darwin CR. 1859. Chapter II — Rio de Janeiro. In: Narrative of the surveying voyages of His Majesty's Ships Adventure and Beagle between the years 1826 and 1836, describing their examination of the southern shores of South America, and the Beagle's 
574

575

576

577

578

579

580

581

582

583

584

585

586

587

588

589

590

591

592

593

594

595

596

597

598

599

600

circumnavigation of the globe. Journal and remarks. 1832-1836: 12-21. Accessed at http://www.gutenberg.org/files/944/944-h/944-h.htm on 01/03/2021.

Day JC. 2011. Parasites, predators and defence of fireflies and glow-worms. In Day JC, ed. Lampyrid: The Journal of Bioluminescent Beetle Research Volume 1. Oxfordshire: Brazen Head Publishing, 70-102.

De Cock R. 2000. Rare, or simply overlooked? Practical notes for survey and monitoring of the small glow-worm Phosphaenus hemipterus (Coleoptera: Lampyridae). Belgian Journal of Zoology 130:93-101.

De Cock R, Matthysen E. 1999. Aposematism and bioluminescence: experimental evidence from glow-worm larvae (Coleoptera: Lampyridae). Evolutionary Ecology 13:619-639. DOI: $10.1023 / \mathrm{A}: 1011090017949$

De Cock R, Matthysen E. 2003. Glow-worm larvae bioluminescence (Coleoptera: Lampyridae) operates as an aposematic signal upon toads (Bufo bufo). Behavioral Ecology 14(1):103-108. DOI: 10.1093/beheco/14.1.103

De Cock R, Matthysen E. 2005. Sexual communication by pheromones in a firefly, Phosphaenus hemipterus (Coleoptera: Lampyridae). Animal Behaviour 70(4):807-818 DOI: 10.1016/j.anbehav.2005.01.011

Douglas HB, Kundrata R, Brunke AJ, Escalona HE, Chapados JT, Eyres J, Richter R, Savard K, Ślipiński A, McKenna D, Dettman JR. 2021. Anchored phylogenomics, evolution and systematics of Elateridae: are all bioluminescent Elateroidea derived click beetles? Biology 10(6):451 DOI: 10.3390/biology10060451

Fallon TR, Lower SE, Chang C, Bessho-Uehara M, Martin GJ, Bewick AJ, Behringer M, Debat HJ, Wong I, Day JC, Suvorov A, Silva CJ, Stanger-Hall KF, Hall DW, Schmitz RJ, Nelson DR, S.M. L, Shigenobu S, Bybee SM, Larracuente AM, Oba Y, Weng JK. 2018. Firefly genomes illuminate parallel origins of bioluminescence in beetles. Elife 7:e36495 DOI: 10.7554/eLife.3649 
601

602

603

604

605

606

607

608

609

610

611

612

613

614

615

616

617

618

619

620

621

622

623

624

625

626

627

628

Fang L, Yang J-W, Wang J-L, Zhu J-Q, Fu X-H. 2013. Preliminary investigation of predation of the snail Bradybaena ravida by larvae of the firefly Pyrocoelia pectoralis. Chinese Journal of Applied Entomology 50(1):197-202.

Faust L. 2012. Fireflies in the snow: Observations on two early-season arboreal fireflies Ellychnia corrusca and Pyractomena borealis. In Kirton LG, Day JC, Lim GT. (ed). Lampyrid: Volume 2 2012: The Journal of Bioluminescent Beetle Research (Lampyrid Journal). Oxfordshire: Brazen Head Publishing, 48-71.

Faust LF. 2017. Fireflies, Glow-worms, and Lightning Bugs. Identification and Natural History of the Fireflies of the Eastern and Central United States and Canada. Athens: University of Georgia Press.

Faust L, Faust H. 2014. The occurrence and behaviors of North American fireflies (Coleoptera: Lampyridae) on milkweed, Ascleplas syriaca L. Coleopterists Bulletin 68(2):283-291. DOI: 10.1649/0010-065X-68.2.283

Faust L, Forrest TG. 2017. Bringing light to the lives of the shadow ghosts, Phausis inaccensa. American Entomologist 63:177-189 DOI doi.org/10.1093/ae/tmx027

Ferreira V, Keller O, Branham M. 2020. Multilocus Phylogeny Support the Nonbioluminescent Firefly Chespirito as a New Subfamily in the Lampyridae (Coleoptera: Elateroidea). Insect Systematics and Diversity 4(6):1-13

Foo K, Seelan J, Dawood M. 2017. Microfungi associated with Pteroptyx bearni (Coleoptera: Lampyridae) eggs and larvae from Kawang River, Sabah (Northern Borneo). Insects 2017, 8, 66 DOI: $10.3390 /$ insects 8030066

Fu X, Ballantyne L, Lambkin C. 2012a. Emeia gen. nov., a new genus of Luciolinae fireflies from China (Coleoptera: Lampyridae) with an unusual trilobite-like larva, and a redescription of the genus Curtos Motsch. Zootaxa 3403:1-53 DOI: $\underline{10.11646 / \text { zootaxa.3403.1.1 }}$

Fu X, Ballantyne L, Lambkin C. 2012b. The external larval morphology of aquatic and terrestrial Luciolinae fireflies (Coleoptera: Lampyridae). Zootaxa 3405:1-34. DOI: 10.11646/zootaxa.3405.1.1

Peer) reviewing PDF | (2021:03:59109:2:0:NEW 24 Jul 2021) 
629

630

631

632

633

634

635

636

637

638

639

640

641

642

643

644

645

646

647

648

649

650

651

652

653

654

655

656

Fu X, Meyer-Rochow VB. 2012. An investigation into the morphological and behavioral adaptations of the aquatic larvae of Aquatica leii (Coleoptera: Lampyridae) to prey upon freshwater snails that serve as intermediate hosts for the liver fluke. Biological Control 62(3):127-134. DOI 10.1016/j.biocontrol.2011.12.007

Fu X, Meyer-Rochow VB. 2013. Larvae of the firefly Pyrocoelia pectoralis (Coleoptera: Lampyridae) as possible biological agents to control the land snail Bradybaena ravida. Biological Control 65(2):176-183. DOI 10.1016/j.biocontrol.2013.02.005

Fu XH, Wang YY, Lei CL. 2005. Adaptive external morphology and swimming behavior in the aquatic firefly, Luciola substriata. Kunchong Zhishi 42(4):419-423.

Fu, XH, Ohba N, Vencl FV, Lei CL. 2005a. Structure, behavior, and the life cycle of an aquatic fir2007efly, Luciola substriata, in China. The Canadian Entomologist 137:83-90 DOI: $\underline{10.4039 / \mathrm{n} 04-022}$

Fu X, Wang Y, Lei C, Ohba N. 2005b. The swimming behavior of the aquatic larvae of the firefly Luciola substriata (Coleoptera: Lampyridae). The Coleopterists Bulletin 59(4):501-505. DOI: https://doi.org/10.1649/830.1

Fu XH, Ohba N, Vencl FV, Lei CL. 2006a. Life cycle and behaviour of the aquatic firefly Luciola leii (Coleoptera: Lampyridae) from Mainland China. The Canadian Entomologist, 138, 860-870. DOI: 10.4039/n05-093

Fu X, Vencl F, Nobuyoshi O, Meyer-Rochow V, Lei CL, Zhang Z. 2007. Structure and function of the eversible glands of the aquatic firefly Luciola leii (Coleoptera: Lampyridae). Chemoecology 17:117-124 DOI: 0.1007/s00049-007-0370-3

Fu X, Meyer-Rochow VB, Tyler J, Suzuki H, De Cock R. 2009. Structure and function of the eversible organs of several genera of larval firefly (Coleoptera: Lampyridae). Chemoecology 19:155-168

Harvey EN, Hall RT. 1929. Will the adult firefly luminesce if its larval organs are entirely removed? Science 69(1783):253-254 DOI: 10.1126/science.69.1783.253

Hess WN. 1920. Notes on the biology of some common Lampyridae. The Biological Bulletin, 38(2):39-76 DOI: 10.2307/1536232 
657

658

659

660

661

662

663

664

665

666

667

668

669

670

671

672

673

674

675

676

677

678

679

680

681

682

683

Hess WN. 1922. Origin and development of the light organs of Photuris pennsylvanica De Geer. Journal of Morphology 36(2):245-277.

Ho JZ, Chiang PH, Wu CH, Yang PS. 2010. Life cycle of the aquatic firefly Luciola ficta (Coleoptera: Lampyridae). Journal of Asia-Pacific Entomology, 13(3):189-196.

Ho JZ, Chiang PH. 2002. Shadows of firefly glowing on the water-the conservation and recovery of aquatic fireflies. Nantou, Chichi: Taiwan Endemic Species Research Institute.

Holt BG, Lessard JP, Borregaard MK, Fritz SA, Araújo MB, Dimitrov D, Fabre PH, Graham CH, Graves GR, Jønsson KA, Nogués-Bravo D, Wang Z, Whittaker RJ, Fjeldså J, Rahbek C. 2013. An update of Wallace's zoogeographic regions of the world. Science, 339(6115): 74-78.

Jeng ML, Lai J, Yang PS. 2003. Lampyridae: A synopsis of aquatic fireflies with description of a new species. In: Jäch, MA, Ji L. eds. Water Beetles of China Vol. III. Wien: Zoologisch-Botanische Gesellschaft in Österreich, Wiener Coleopterologenverein, 539562.

Joly S, Davies TJ, Archambault A, Bruneau A, Derry A, Kembel SW, Peres-Neto P, Vamosi J, Wheeler TA. 2014. Ecology in the age of DNA barcoding: the resource, the promise and the challenges ahead. Molecular Ecology Resources, 14(2), 221-232.

Kakehashi K, Kuranishi RB, Kamata N. 2013. Environmental factors affecting the spatial distribution and activity of firefly larvae Luciola parvula (Coleoptera: Lampyridae: Luciolinae): high activity under rich soil moisture. Japanese Journal of Conservation Ecology 18:45-54.

Kaufmann T. 1965. Ecological and Biological Studies on the West African firefly Luciola discicollis (Coleoptera: Lampyridae). Annals of the Entomological Society of America 58(4):414-426.

Kok PJ, van Doorn L, Dezfoulian R. 2019. Predation by non-bioluminescent firefly larvae on a tepui-summit endemic toad. Current Biology, 29(22), R1170-R1171 Doi: $\underline{10.1016 / j . c u b .2019 .10 .001}$

Peer] reviewing PDF | (2021:03:59109:2:0:NEW 24 Jul 2021) 
684

685

686

687

688

689

690

691

692

693

694

695

696

697

698

699

700

701

702

703

704

705

706

707

708

709

710

Kundrata R, Bocakova M, Bocak L. 2014. The comprehensive phylogeny of the superfamily Elateroidea (Coleoptera: Elateriformia). Molecular Phylogenetics and Evolution 76:162-171 DOI: 10.1016/j.ympev.2014.03.012

Kusy D, He J-W, Bybee SM, Motyka M, Bi W-X, Podsiadlowski L, Li X-Y, Bocak L. 2021. Phylogenomic relationships of bioluminescent elateroids define the 'lampyroid' clade with clicking Sinopyrophoridae as its earliest member. Systematic Entomology 46:111-123. DOI: $10.1111 /$ syen.12451

Lawrence JF, Ślipiński A, Seago AE, Thayer MK, Newton AF, Marvaldi AE. 2011. Phylogeny of the Coleoptera based on morphological characters of adults and larvae. Annals of Zoology (Warszawa) 61:1-217 DOI: 10.3161/000345411X576725

Lewis SM, Cratsley CK. 2008. Flash Signal Evolution, Mate Choice, and Predation in Fireflies. Annual Review of Entomology 53(1):293-321 DOI:

\subsection{6/annurev.ento.53.103106.093346}

Lloyd JE. 1973. Firefly Parasites and Predators. The Coleopterists Bulletin 27:91-106.

Madruga-Rios O, Hernández-Quinta M. 2010. Larval feeding habits of the Cuban endemic Firefly Alecton discoidalis Laporte (Coleoptera: Lampyridae). Psyche 2010, ID 149879 DOI: $10.1155 / 2010 / 149879$

Martin GJ, Stanger-Hall KF, Branham MA, Da Silveira LF, Lower SE, Hall DW, Li XY, Lemmon AR, Moriarty-Lemmon E, Bybee SM. 2019. Higher-level phylogeny and reclassification of Lampyridae (Coleoptera: Elateroidea). Insect Systematics and Diversity 3(6):ixz024 DOI 10.1093/isd/ixz024

McDermott FA. 1964. The Taxonomy of the Lampyridae (Coleoptera). Transactions of the American Entomological Society 90(1): 1-72.

McDermott FA. 1966. Lampyridae. In: Steel, WO, ed. Coleopterorum Catalogus Supplementa. Pars 9. 2.ed. The Hague: W. Junk.

McKenna DD, Shin S, Ahrens D, Balke M, Beza-Beza C, Clarke DJ, Donath A, Escalona HE, Friedrich F, Letsch H, Liu S, Maddison D, Mayer C, Misof B, Murin 
711

712

713

714

715

716

717

718

719

720

721

722

723

724

725

726

727

728

729

730

731

732

733

734

735

736

737

738

PJ, Niehuis O, Peters RS, Podsiadlowski L, Pohl H, Scully ED, Yan EV, Zhou X, Ślipiński A, Beutel RG. 2019. The evolution and genomic basis of beetle diversity. Proceedings of the National Academy of Science USA 116:24729-24737 DOI: $\underline{10.1073 / \text { pnas. } 1909655116}$

McKenna DD, Wild AL, Kanda K, Bellamy CL, Beutel RG, Caterino, MS, Farnum CW, Hawks DC, Ivie MA, Jameson ML, Leschen RAB, Marvaldi AE, Mchugh JV, Newton AF, Robertson JA, Thayer MK, Whiting MF, Lawrence JF, Lipiski A, Maddison DR, Farrell BD. 2015. The beetle tree of life reveals that Coleoptera survived end-Permian mass extinction to diversify during the Cretaceous terrestrial revolution. Systematic Entomology 40:835-880 DOI: 10.1111/syen.12132

McLean M, Buck J, Hanson F. 1972. Culture and larval behavior of photurid fireflies. The American Midland Naturalist 87(1):133-145 DOI: $10.2307 / 2423887$

Nada B, Ballantyne LA, Jusoh WFA. 2021. Description of the larva of a firefly species, Pygoluciola dunguna Nada (Coleoptera: Lampyridae). Zootaxa 4920(4):528-542 DOI: $\underline{10.11646 / \text { zootaxa.4920.4.4 }}$

Novák M. 2018a. Redescription of immature stages of central European fireflies, Part 2: Lamprohiza splendidula (Linnaeus, 1767) larva, pupa and notes on its life cycle and behaviour (Coleoptera: Lampyridae). Zootaxa 4378(4):516-532 DOI: $\underline{10.11646 / \text { zootaxa.4378.4.4 }}$

Novák M. 2018b. Redescription of immature stages of central European fireflies, Part 3: Phosphaenus hemipterus (Goeze, 1777) larva, pupa and notes on its life cycle and behaviour, with a key to three Central European lampyrid larvae (Coleoptera: Lampyridae). Zootaxa 4382(3):450-464 DOI: 10.11646/zootaxa.4382.3.2

Nunes VCS, Matos EJM, Lima W, Vaz S, Mermudes JRM, Silveira LFS. 2021. Lights Ahead: morphology and life stages of the spotted tortoise firefly, Aspisoma sticticum Gemminger, 1870 - fireflies with a unique extra pair of lanterns on the larval pronotum (Coleoptera: Lampyridae). Annales Zoologici 71(1):153-178 DOI: $\underline{10.3161 / 00034541 \mathrm{ANZ2021.71.1.007}}$ 
Oertel D, Case JF. 1976. Neural excitation of the larval firefly photocyte: slow

740

741

742

743

744

745

746

747

748

749

750

751

752

753

754

755

756

757

758

759

760

761

762

763

764

765

766

767 depolarization possibly mediated by a cyclic nucleotide. Journal of Experimental Biology 65:213-227.

Ohba N, Goto Y, Kawashima I. 1996. External morphology, color-making patterns and habitats of the larval stage in genus Stenocladius (Coleoptera: Lampyridae). Science Reports of the Yokosuka City Museum 44:21-31.

R Core Team. 2019. R: A language and environment for statistical computing. $R$ Foundation for Statistical Computing, Vienna, Austria. Available at https://www.Rproject.org/

Rosa, SP, Costa C, Kramp K, Kundrata, R. 2020. Hidden diversity in the Brazilian Atlantic rainforest: the discovery of Jurasaidae, a new beetle family (Coleoptera, Elateroidea) with neotenic females. Scientific Reports 10:1544 DOI: 10.1038/s41598-02058416-6

Sato N. 2019. Prey-tracking behavior and prey preferences in a tree-climbing firefly. PeerJ 7:e8080 DOI: $10.7717 /$ peerj.8080

Silveira LF, Khattar G, Vaz S, Wilson VA, Souto PM, Mermudes JR, Stanger-Hall KF, Macedo MV, Monteiro RF. 2020. Natural history of the fireflies of the Serra dos Órgãos mountain range (Brazil: Rio de Janeiro) - one of the 'hottest' firefly spots on Earth, with a key to genera (Coleoptera: Lampyridae). Journal of Natural History, 54(5-6): 275308.

Sivinski J. 1981. The Nature and possible functions of luminescence in Coleoptera larvae. The Coleopterists Bulletin 35(2):167-179

Sivinski JM, Lloyd JE, Beshers SN, Davis LR, Sivinski RG, Wing SR, Sullivan RT Peterson E. 1998. A natural history of Pleotomodes needhami Green (Coleoptera: Lampyridae): a firefly symbiont of ants. The Coleopterists Bulletin 52(1):23-30.

Stanger-Hall KF, Sander SE, Lundberg L, Hopkins A, Pallansch J, Hall DW. 2018. The evolution of sexual signal mode and associated sensor morphology in fireflies (Lampyridae, Coleoptera). Proceedings of the Royal Society B 285(1871):20172384 http://dx.doi.org/10.1098/rspb.2017.2384 
Stansbury MS, Moczek AP. 2014. The function of Hox and appendage-patterning genes in the development of an evolutionary novelty, the Photuris firefly lantern. Proceedings of the Royal Society B 281(1782):20133333 DOI: 10.1098/rspb.2013.3333

771

772

773

774

775

776

777

778

779

780

781

782

783

784

785

786

787

788

789

790

791

792

793

794

795

Thancharoen A, Ballantyne LA, Branham MA, Jeng ML. 2007. Description of Luciola aquatilis sp. nov., a new aquatic firefly (Coleoptera: Lampyridae: Luciolinae) from Thailand. Zootaxa 1611:55-62 DOI: 10.11646/zootaxa.1611.1.4

Tisi LC, De Cock R, Stewart AJA, Booth D, Day JC. 2014. Bioluminescent leakage throughout the body of the glow-warm Lampyris noctiluca (Coleoptera: Lampyridae). Entomologia Generalls 35(1):47-51 DOI: $\underline{10.1127 / 0171-8177 / 2014 / 0003}$

Tonolli PN, Okawachi FM, Abdalla FC, Viviani VR. 2011. Bioluminescent fat body of larval Aspisoma lineatum (Coleoptera: Lampyridae) firefly: ontogenic precursor of lantern's photogenic tissue. Annals of the Entomological Society of America 104(4):761767 DOI: $\underline{\text { doi.org/10.1603/AN10143 }}$

Tyler J. 1997b. A two-headed larva of the glow-worm Lampyris noctiluca Linnaeus (Lampyridae). Coleopterist 6(2):67.

Tyler J. 2001a. Are glow-worms Lampyris noctiluca (Linnaeus) (Lampyridae) distaestful? The Coleopterist 9(3): 148.

Tyler J. 2001b. A previously undescribed defence mechanism in the larval glow-worm Lampyris noctiluca (Linnaeus)? The Coleopterist 10(2):38

Tyler J. 2002. Glow-worms. Sevenoaks: Tyler-Scagell.

Tyler J, Trice E. 2001. A description of a possible defensive organ in the larvae of the European Glow-worm Lampyris noctiluca (Linnaeus) (Lampyridae). The Coleopterist 10(3):75-78.

Underwood TJ, Tallamy DW, Pesek JD. 1997. Bioluminescence in firefly larvae: a test of the aposematic display hypothesis (Coleoptera: Lampyridae). Journal of Insect Behavior 10:365-370 DOI: $\underline{10.1007 / \mathrm{BF} 02765604}$

Vaz S, Silveira LFL, Rosa SP. 2020. Morphology and life cycle of a new species of Psilocladus Blanchard, 1846 (Coleoptera, Lampyridae, Psilocladinae), the first known 
796

797

798

799

800

801

802

803

804

805

806

807

808

809

810

811

812

813

814

815

816

817

818

819

820

bromeliad-inhabiting firefly. Papéis Avulsos de Zoologia 60(spe): e202060(s.i.)24 DOI: 10.11606/1807-0205/2020.60.special-issue.24

Vaz SNC, Guerrazzi MC, Rocha M, Faust LF, Gabriel Khattar G, Mermudes JRM, Silveira LFL. 2021. On the intertidal firefly genus Micronaspis Green, 1948, with a new species and a phylogeny of Cratomorphini based on adult and larval traits (Coleoptera: Lampyridae). Zoologischer Anzeiger, 292: 64-91.

Vencl FV, Shah S, Gerber A, Carlson AD. 2012. Octopamine and DUM neurons orchestrate the larval firefly aposematic defense. In Kirton LG, Day JC, Lim GT. (ed). Lampyrid: Volume 2 2012: The Journal of Bioluminescent Beetle Research (Lampyrid Journal). Oxfordshire: Brazen Head Publishing, 99-112.

Viviani VR, Rosa SP, Martins MA. 2012. Aspisoma lineatum (Gyllenhal) (Coleoptera: Lampyridae) firefly: description of the immatures, biological, and ecological aspects. Neotropical Entomology 41:89-94 DOI: 10.1007/s13744-011-0006-8

Viviani VR, Arnoldi FGC, Brochetto-Braga M, Ohmiya Y. 2004. Cloning and characterization of the cDNA for the Brazilian Cratomorphus distinctus larval firefly luciferase: similarities with European Lampyris noctiluca and Asiatic Pyrocoelia luciferases. Comparative Biochemistry and Physiology, Part B 139(2):151-156.

Wickham H. 2009. Ggplot2: Elegant Graphics for Data Analysis. 2nd Edition, Springer, New York. https://doi.org/10.1007/978-0-387-98141-3

Williams FX. 1917b. Photogenic organs and embryology of some lampyrids. Journal of Morphology 28(1):145-207.

Zhang Q-L, Guo J, Deng X-Y, Wang F, Chen, J-Y, Lin L-B. 2019. Comparative transcriptomic analysis provides insights into the response to the benzo(a)pyrene stress in aquatic firefly (Luciola leii). Science of the Total Environment 661:226-234 DOI 10.1016/j.scitotenv.2019.01.156

Peer) reviewing PDF | (2021:03:59109:2:0:NEW 24 Jul 2021) 


\section{Figure 1}

Generalized morphology of a firefly larva.

A) lateral view, insets show key traits. hd: head and cervical membrane; md: mandible; po:

pleural organ; pg: pygopodium; ts/tg: tracheal spiracle/tracheal gill; tb: tubercles. B-E)

variation in lantern disposition. The most common pattern is the scheme in $\mathrm{B})-\mathrm{C})$; Pterotus is an example of D); E) is only known in Lamprohiza. 

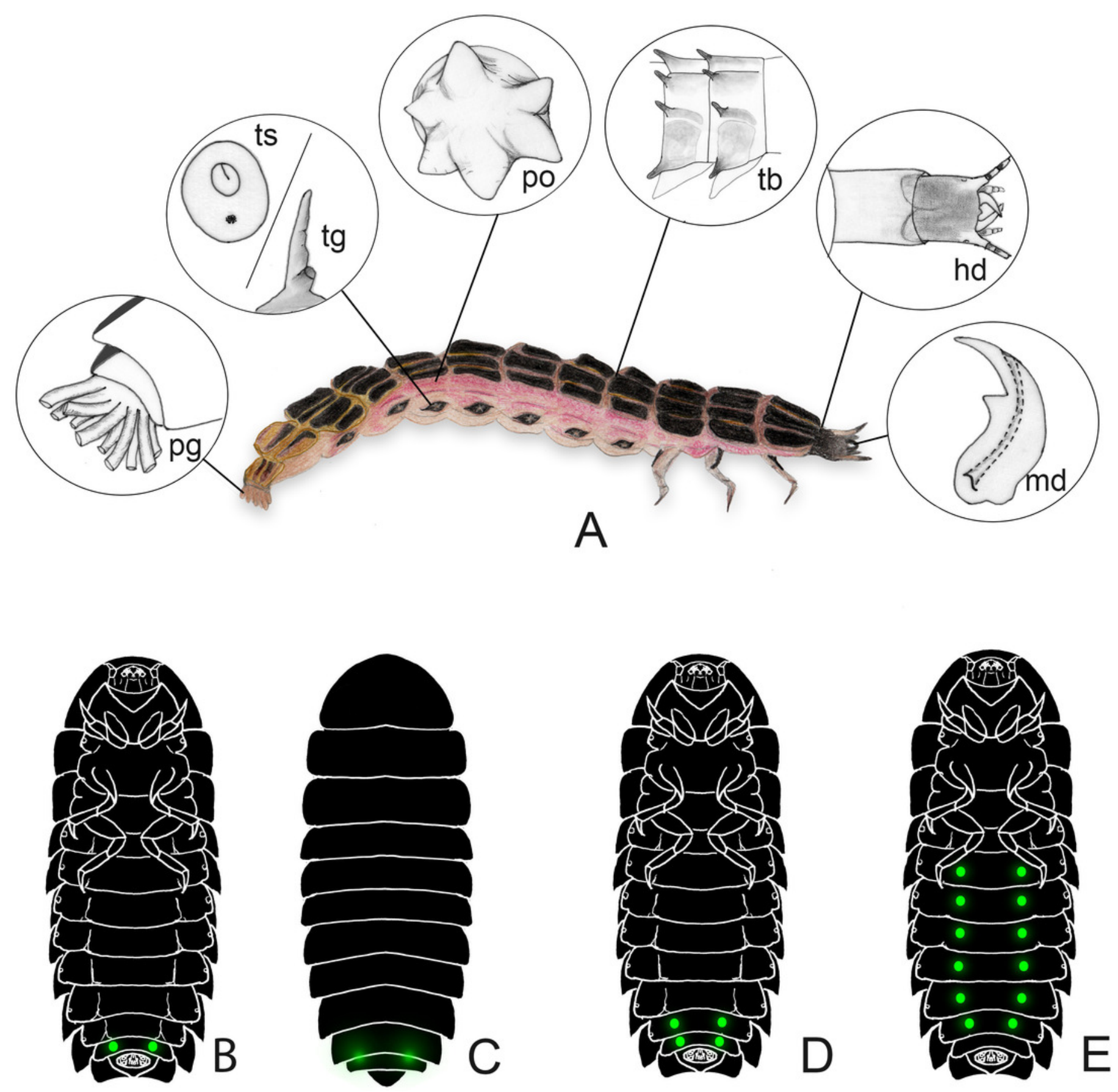


\section{Figure 2}

Firefly larvae vary from a flat (with tergites laterally expanded) to slender outline, with intermediate forms. The legs can be short to very long. Aquatic species often have reduced sclerites, sometimes divided into individualized plates, and might have

Figures A-H illustrates the diversity of larval outlines: A) long legs and laterally expanded terga (e.g. Cratomorphus); B) terga with tubercles (e.g. Luciola hypocrita); C) terga narrow with lateral pleurae visible in dorsal view (e.g. Photinus); D) pleurae dorsally visible with paired tracheal gills (e.g. Aquatica); E-F) elliptical larvae with terga expanded (e.g. Photuris and Lamprigera); G) arboreal larvae are usually slender and somewhat flat (e.g. Pyrocoelia atripennis ); H) fossorial larvae are somewhat cylindrical (e.g. Photinus). 

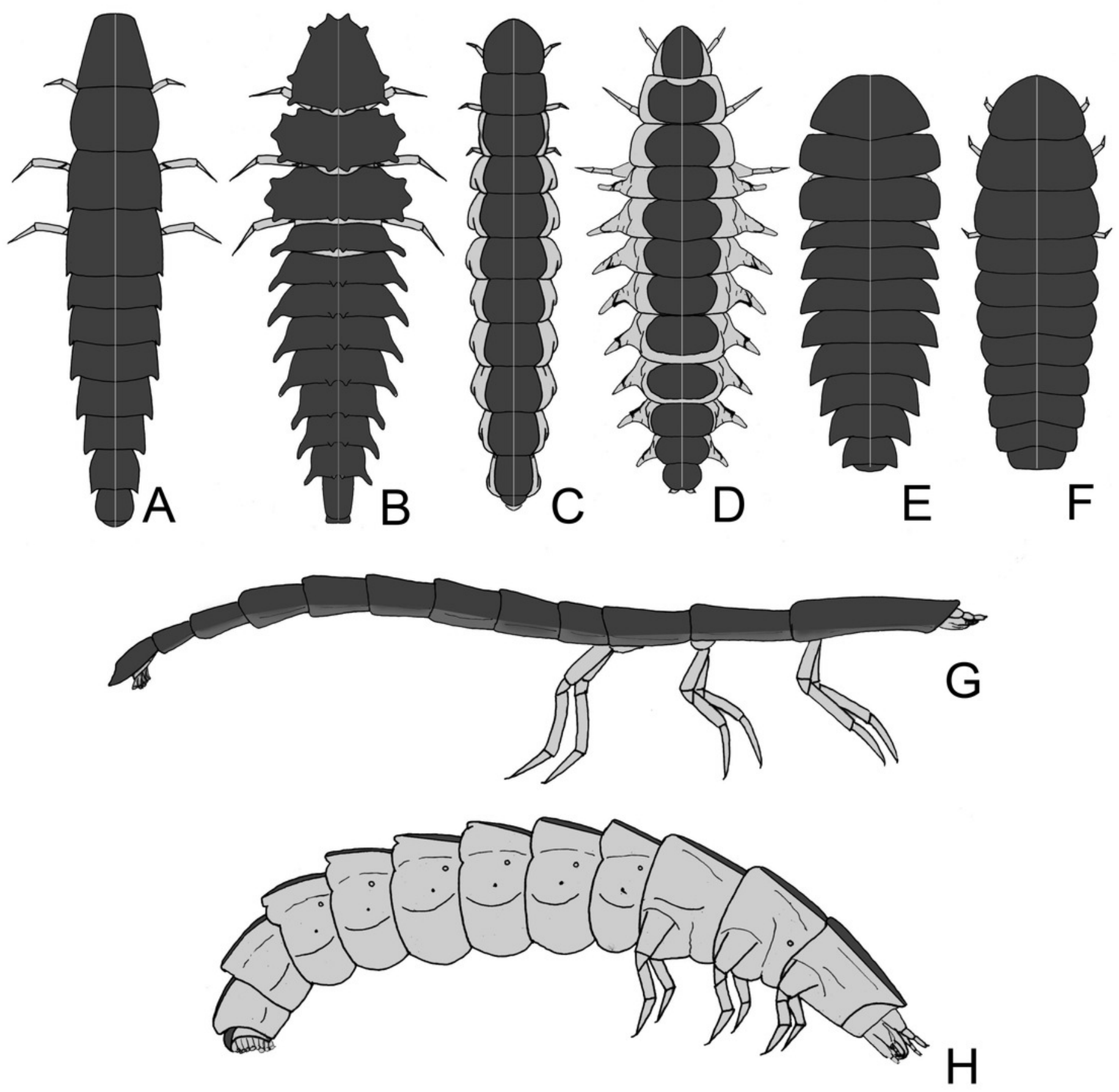


\section{Figure 3}

$82 \%$ of species with any study on their immature stages are in two subfamilies:

Luciolinae and Lampyrinae, as revealed in a plot of the number of species with at least one study with information on their immature stages.

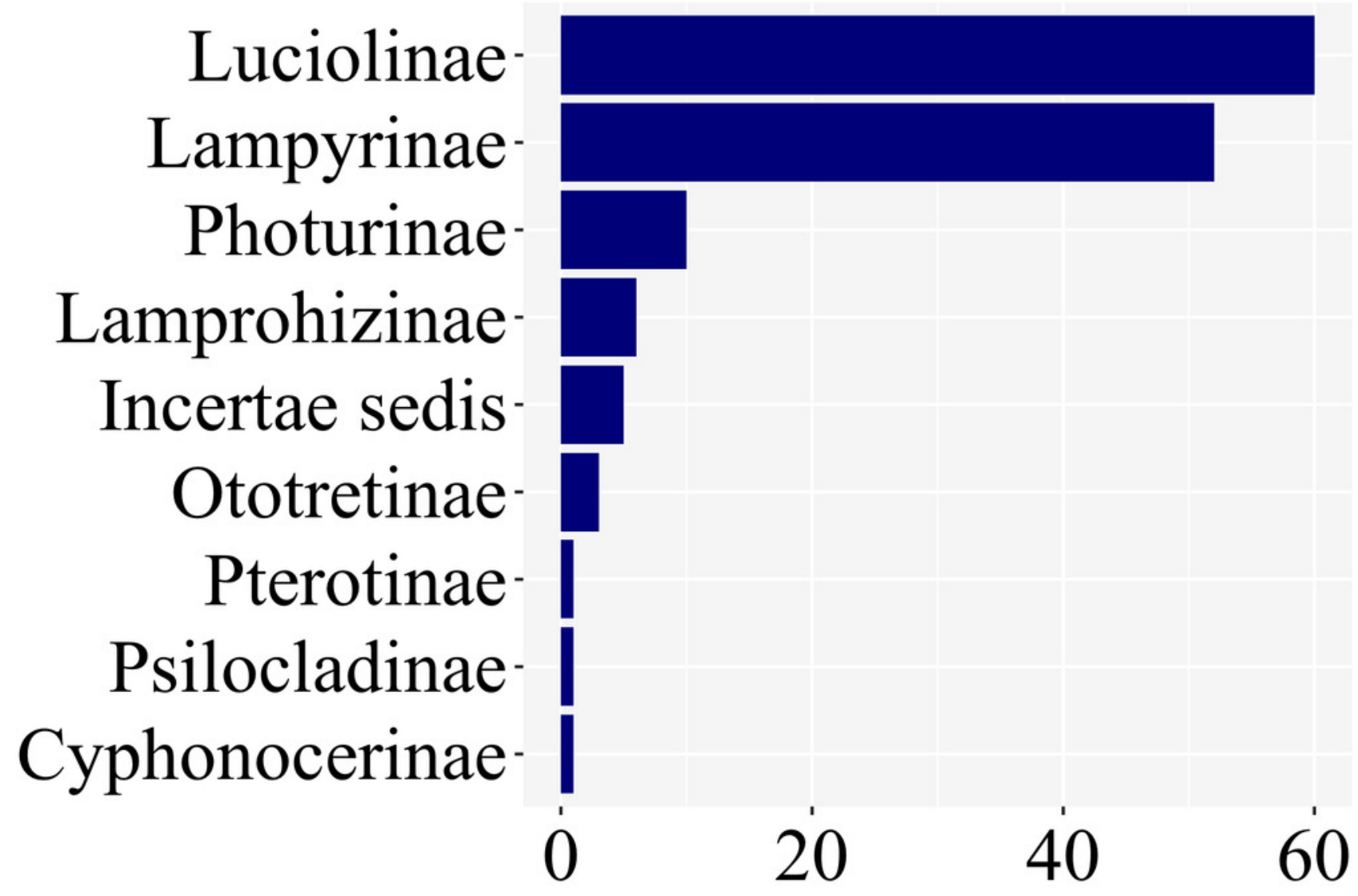


Figure 4

About $80 \%$ of studies on firefly larvae deal with species in two subfamilies, Luciolinae and Lampyrinae, as revealed in a plot of the number of studies per subfamily.

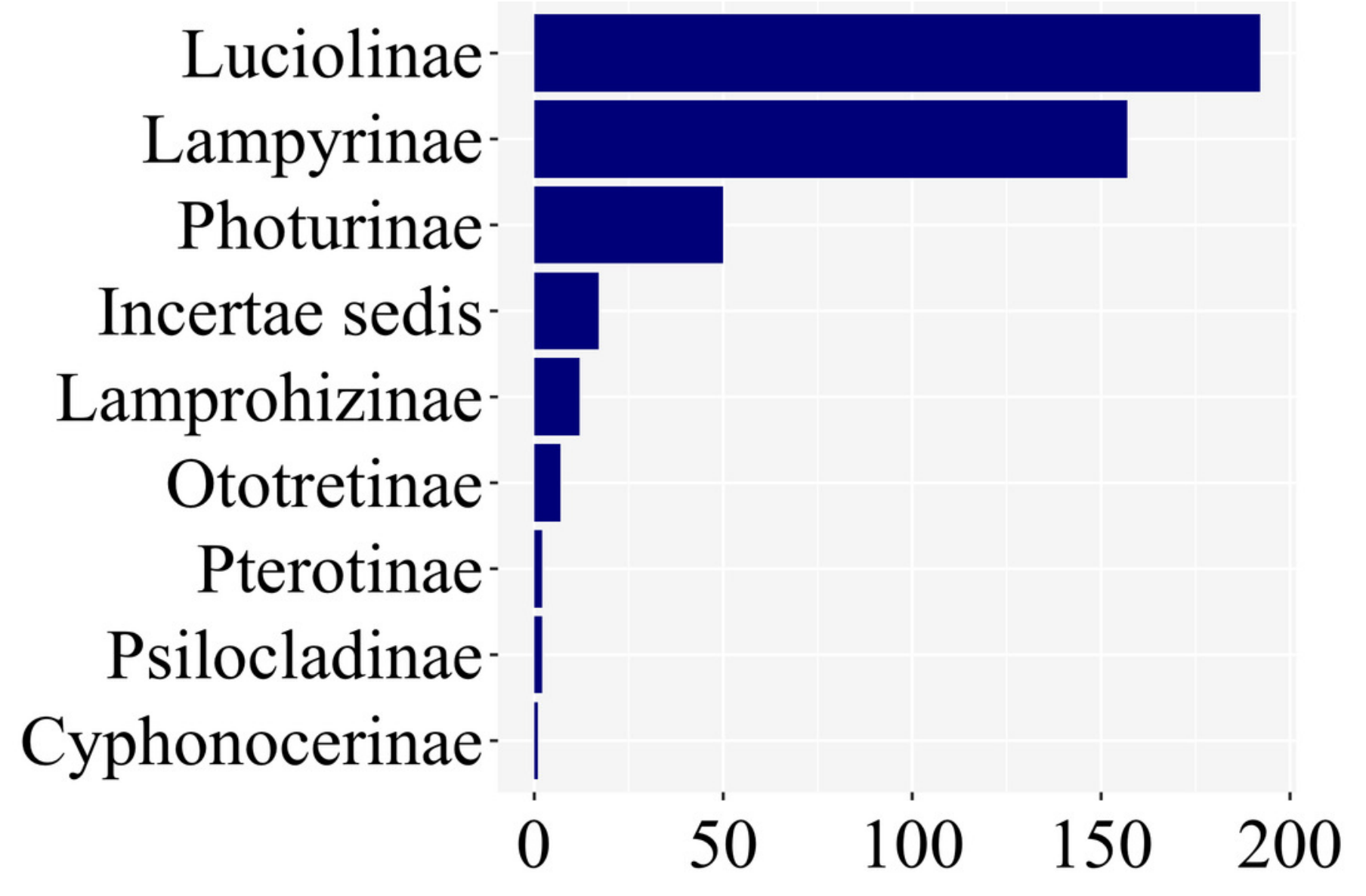




\section{Figure 5}

Nearly $85 \%$ of studies on firefly larvae are concentrated in four zoogeographic regions: Sino-Japanese, Nearctic, Oriental and Palearctic - as revealed in a plot of number of studies per region.

Sino-Japanese-

Nearctic-

Oriental-

Palearctic-

Neotropical-

Oceanian-

Australian-

Panamanian-

Saharo-Arabian-

Afrotropical-

Madagascan-
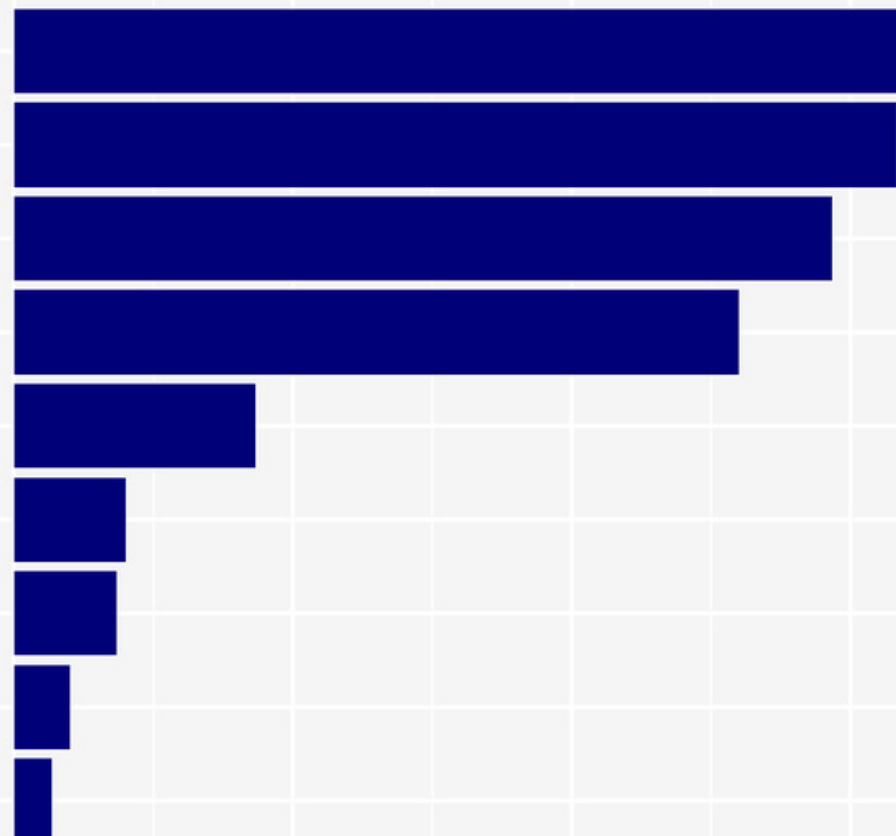

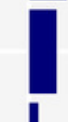

$\begin{array}{lllll}0 & 30 & 60 & 90 & 120\end{array}$




\section{Figure 6}

Morphology and behavior are the most commonly addressed aspect of firefly biology ( $53 \%$ of the studies), as revealed in a plot of number of studies per subject.

Morphology-

Behavior-

Life cycle-

Habitat-

Physiology-

Interactions -
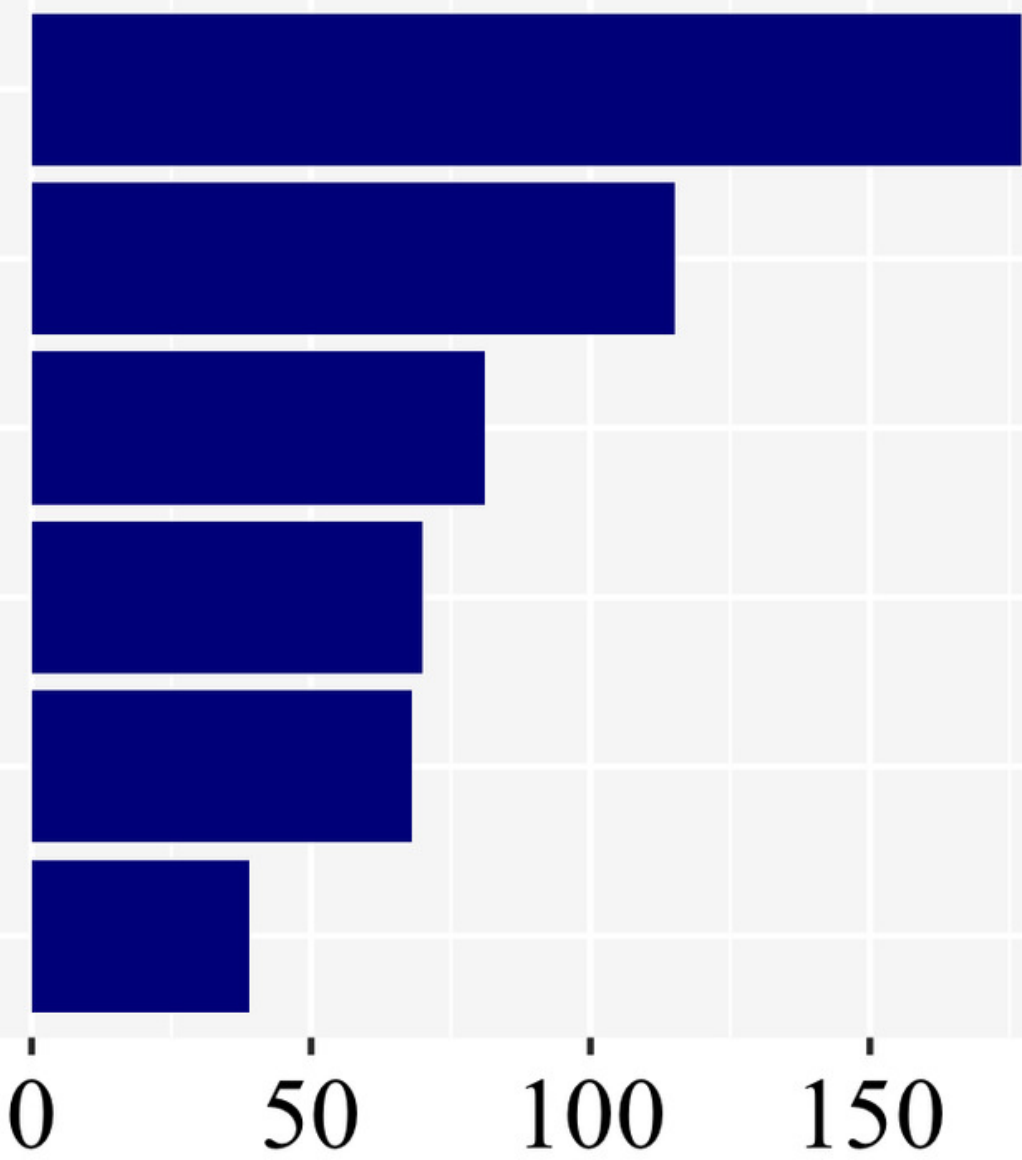